\title{
IMPRENSA, MINORIAS E ANÁLISE DO DISCURSO - UM ESPAÇO DE CONSTRUÇÃO DA DEMOCRACIA
}

\section{André Ricardo Nunes Martins}

"Para construir a democracia há que imaginá-la."

(Norbert Lechner)

\begin{abstract}
:
In this paper, we consider the discursive process in the Press and the minorities representation as an example of racism present in the Brazilian society. The relation Press, minorities and discourse analyse can constitute a space for constructing and empowering democracy in Brazilian society. It shows how language is used to produce ideological meanings of racism, criticize that reality and to point to overcoming those inequalities, expanding democracy.
\end{abstract}

KEYWORDS: Press; minorities; discourse analysis; racism; democracy.

INTRODUÇ̃̃o

Nas últimas décadas, os estudos sobre diferenças étnicas e de gênero, as minorias e o racismo vêm ganhando força nas ciências sociais. Nota-se no panorama social e político mundial uma crescente luta de grupos minoritários pelo poder, pela busca de oportunidades, pelo acesso a bens materiais e simbólicos. Por outro lado, há também uma crítica implícita ao desequilíbrio do poder, às desigualdades sociais e à forma como a ciência, a linguagem e o conhecimento são utilizados para justificar essas desigualdades.

A conjuntura propiciada pela modernidade tardia gera efeitos também sobre a prática discursiva das pessoas no interior das instituições, o que produz fenômenos como a valorização dos eventos de letramento, a luta ideológica na produção do discurso e no conflito de sentidos entre igualdade e diferença. Quanto a essa nova conjuntura, Chouliaraki e Fairclough (1999) notam que 
as mudanças econômicas, sociais e culturais existem como discursos e como processos fora do discurso, mas que, no entanto, mesmo esses processos fora do discurso são constituídos por este.

Vale o questionamento, seria o discurso tudo, manifestando assim a faculdade da ubiqüidade? Os autores dizem que 'não', com o que também concordamos. E, recuperando o que propõe Harvey, apontam para os momentos da realidade social: as relações sociais, o poder, as práticas sociais, crenças/ valores/desejos e instituições/rituais. Entre essas realidades há uma relação dialética (Chouliaraki \& Fairclough, 1999).

Nesse contexto, analistas do discurso têm valorizado a transdisciplinaridade como uma perspectiva de investigação, em especial na compreensão dos fenômenos sociais que têm sofrido profundo impacto com a modernidade tardia. Como Chouliaraki e Fairclough defendem, as construções teóricas do discurso podem advir de várias disciplinas. A ‘operacionalização’ implica teorizar num meio transdisciplinar em que a lógica de uma teoria pode ser "posta para atuar" no desenvolvimento de outra, sem que a segunda se reduza à primeira.

Outra questão relevante na nova conjuntura trazida pela globalização diz respeito à democracia, expandindo-a de um mero enquadramento como regime político com algumas características formais para uma compreensão mais abrangente que a considere em referência à diversidade de interesses no interior de uma dada sociedade e ao respeito a grupos minoritários. Comumente nos textos da imprensa, a democracia é apresentada como o regime de governo predominante nos países do Ocidente. Fala-se de países com mais ou menos democracia ou de países com maior ou menor tradição democrática ou ainda de países com maior ou menor estabilidade democrática. Mas, em geral, seriam quase todos democráticos. Hoje, a exceção em nosso continente seria Cuba e, para alguns, a Venezuela ${ }^{1}$. Por essa perspectiva, o que importa não é a igualdade de direitos que o regime democrático pressupõe, mas tão somente, a observância do aspecto formal do processo político.

\footnotetext{
${ }^{1}$ Dois dos principais jornais brasileiros trataram da situação política na Venezuela em 10/01/07, ambos apontando uma suposta escalada rumo à ditadura do governo Chávez. A Folha de S. Paulo, o título foi "O Rubicão de Chávez" e no jornal O Estado de São Paulo, "A escalada autocrática de Chávez."
} 
Touraine (1994:345) nos fala porém de uma perspectiva democrática que combina uma integração da cidadania, "que supõe em primeiro lugar a liberdade das escolhas políticas, com o respeito das identidades, das necessidades e dos direitos." A propósito, consideremos o poder controlado e exercido pelas grandes corporações, as limitações impostas a grupos minoritários e as desigualdades relativas à distribuição dos bens materiais e simbólicos e concluiremos que a democracia é, quando muito, um regime em construção em todos os países que se dizem democráticos.

No Brasil, uma questão - a um só tempo crônica e urgente - se impõe, a saber, como reparar as injustiças praticadas secularmente contra os africanos vindos para o Brasil e seus descendentes e como promover a ascensão social dessas pessoas, superando o fosso das desigualdades raciais manifestas de tantas formas. Os governos e a sociedade devem encarar a contradição, o nó górdio do processo democrático: depois da abolição da escravatura, o que efetivamente o Estado brasileiro - que chegou a patrocinar durante mais de cem anos a vinda de imigrantes europeus, facilitando sua integração à ordem econômica nacional e à sociedade - o que este Estado tem a dizer aos descendentes dos escravos declarados libertos em maio de 1888? Que democracia é essa que se recusa a combater as desigualdades raciais e a adotar políticas efetivas de promoção da população afrodescendente?

Neste artigo, queremos examinar o papel da análise do discurso - haja vista sua relevância política e o potencial para trabalhar a transdisciplinaridade - como um instrumental teórico-prático eficaz para investigar o tratamento que é dado às minorias raciais no Brasil e, ao mesmo tempo, discutir questões que contribuam no sentido de municiar essas mesmas minorias na busca da ampliação de seu espaço no discurso da imprensa e na opinião pública de um modo geral em meio a esse processo democrático em construção.

\section{O DISCURSO DA IMPRENSA E A REPRESENTAÇÃO DAS MINORIAS}

Em teoria, a imprensa veicula notícias de interesse público, está aberta à discussão de assuntos demandados pela coletividade, propiciando igualmente acesso livre e fácil aos vários grupos sociais. Na prática, não é assim que as coisas funcionam. Efetivamente, a imprensa, como instituição social, é atravessada por interesses diversos e não raro antagônicos. 
Desde meados do século XX, a imprensa ${ }^{2}$ em vários países do Ocidente, o Brasil entre eles, vem apresentando alguns fenômenos entre os quais a redução no número de jornais diários, a concentração das empresas nas grandes cidades ou em cidades de porte médio, a dependência quase absoluta do mercado da publicidade e das estratégias de marketing e o suporte dado à ordem sócio-política e econômica. Em grande medida, as mudanças correspondem aos desdobramentos havidos no capitalismo, como a globalização, por exemplo.

É quase impossível conceber as sociedades contemporâneas sem a intervenção da imprensa. O conhecimento do que se passa desde o ambiente mais próximo das pessoas até os países mais distantes, o processo político, o comércio, a diplomacia, tudo isso requer, como pré-requisito a seu pleno desenvolvimento, o trabalho rotineiro e permanente da imprensa.

Deixando de lado uma concepção tradicional e ingênua segundo a qual o papel da imprensa é informar, vemos que a imprensa é não somente veiculadora, mas produtora de sentidos, ou seja, os profissionais da imprensa - ao apresentarem resumos de fatos e fenômenos (notícias) dos indivíduos e grupos sociais - atribuem e reelaboram significados, apresentam-nos de uma certa posição e perspectiva e dirigem-se mais a algumas pessoas do que a outras. Temos assim uma hierarquização no trabalho dos jornalistas já que nem tudo é notícia e nem toda notícia recebe o mesmo tratamento. O que a imprensa faz, portanto, é um trabalho de construção da realidade. E para esse trabalho concorrem fatores de ordem ideológica. Aqui, tomamos ideologia como a definiu J. B. Thompson (1998): sentido a serviço do poder.

À manipulação ideológica operada na imprensa vincula-se, portanto, um processo mais amplo de luta motivada por questões relacionadas ao poder como o poder de controlar a representação dos atores sociais, a manifestação das vozes dos participantes no interior do discurso, os assuntos que vão ser priorizados e o destaque dado a eles etc. O reconhecimento da intervenção da ideologia no discurso da imprensa mediante as diversas formas apontadas

\footnotetext{
${ }^{2}$ Em O monopólio da mídia (1990), B. Bagdikian faz uma análise muito percuciente sobre a realidade da imprensa nos EUA, apontando os fenômenos que citamos aqui e ilustrando com dados bem pontuais. Com as devidas ressalvas, a realidade brasileira apresenta muitas semelhanças em relação ao caso americano.
} 
por Thompson é que propicia a leitura crítica dos textos da imprensa. Isso não significa que no exame de textos específicos não se perceba a influência de aspectos como limitações de recursos, de espaços, perspectivas conjunturais (crises, distanciamento do fato etc.) e mesmo diferenças de tratamento de um assunto entre os diversos jornalistas e os vários veículos. Não se trata disso, mas sim de reconhecer que também esses aspectos são direta ou indiretamente resultado de uma luta ideológica que se dá tanto na sociedade como um todo, como na instituição imprensa.

O discurso da imprensa tem papel fundamental na constituição dos papéis sociais. Referindo-se às sociedades contemporâneas, van Dijk (1991) atribui à imprensa um controle quase exclusivo sobre os recursos simbólicos com os quais se produz o consenso popular, especialmente no que diz respeito às relações étnicas.

Como mostramos em outro trabalho (Martins, 2004: 61), "o prestígio com que se reveste a intervenção de atores sociais na imprensa e a atuação dos jornalistas junto às elites representam, já por si, uma força considerável na luta pelo estabelecimento de sentidos no processo discursivo". No mesmo trabalho, observamos que, na discussão pública em torno da política de cotas para negros nas universidades, uma das estratégias discursivas desenvolvidas foi a de exclusão do movimento negro como ator social relevante. Da exclusão direta à subvalorização das vozes da liderança e de militantes negros, opta-se por negar papel relevante ao movimento negro como ator social.

O discurso da imprensa não favorece os grupos étnicos minoritários, antes ele opera, contribuindo, a seu modo, para o fortalecimento e a reprodução do racismo, na medida em que exclui ou minimiza a visibilidade desses grupos na cena pública, não prioriza questões de interesse dessas minorias ou vincula-os sistematicamente à falta de instrução, à pobreza, à violência, à perturbação da ordem etc. Sendo a mídia em geral e a imprensa em particular uma arena de luta política de primeira grandeza, as minorias estão em desvantagem no processo de participação política.

Para van Dijk (1996), a dominação étnico-racial que sintetiza o racismo é reproduzida não simplesmente por causa do acesso diferenciado à moradia, empregos, aluguéis, educação ou bem-estar, mas também por meio de padrões diferenciados de acesso ao discurso. O poder de acesso preferencial à mídia 
está intimamente ligado ao poder que as elites têm em definir a situação étnica e de, portanto, contribuir para a reprodução do racismo.

Um dos aspectos a se considerar é a baixa participação de representantes de grupos minoritários nas redações, o que favorece não um olhar próprio, mas um olhar do outro. Nesse sentido, note-se que a ausência, por exemplo, de uma diversidade étnica entre os profissionais da imprensa, necessária à pluralidade de percepções e 'posições pessoais, hábitos e emoções' no ambiente mesmo das redações é objeto de uma discussão antiga nos EUA e em outros países. No Brasil, no entanto, ela ainda não se impôs, o que deve ser visto como mais um sintoma do mal estar relacionado à discussão das relações raciais no país.

No trabalho de I. Law (2002), percebe-se como os textos da mídia têm um papel chave tanto em desafiar identidades fixas e as perspectivas a elas relacionadas como em propor e transmitir idéias e imagens que influenciam e formam novas visões de mundo. Esse investimento racista por parte da imprensa não é comumente percebido pelas pessoas em geral. O espaço dedicado a artistas negros ou a atividades culturais em que os negros têm reconhecido papel de destaque aliado a alguns profissionais negros de sucesso nos meios de massa pode, ao contrário, sugerir a idéia de que não há discriminação contra as minorias por parte de empresas jornalísticas.

\section{O CASO DA AÇÃO AFIRMATIVA}

A emergência da discussão pública ${ }^{3}$ sobre a necessidade e a viabilidade da política de cotas para negros nas universidades em 2002 e 2003 trouxe à tona mais uma vez o debate sobre o racismo à brasileira. A medida tem sido vista como uma das possibilidades de intervenção política na realidade brasileira para combater as desigualdades raciais que penalizam a comunidade negra, uma vez que pode auxiliar na ascensão social de milhares de afrodescendentes e suas famílias.

No Brasil, o ensino privado, da educação infantil ao ensino médio, é considerado melhor e mais eficiente que o ensino público. Só no ensino

\footnotetext{
${ }^{3}$ Em pesquisa para o doutoramento em Lingüística, analisamos o discurso da imprensa sobre a política de cotas, examinando três jornais de grande circulação, Folha de S. Paulo, Jornal do Brasil e A Tarde, escolhendo textos de seis gêneros discursivos que abordaram o assunto no período de janeiro de 2002 a dezembro de 2003 (ver referências bibliográficas).
} 
superior a situação se inverte: a universidade pública, em geral, tem melhores condições de ensino e prestígio que a particular. O corolário dessa equação é simples: aqueles alunos que tiveram melhores condições de estudo são os mais capacitados a conquistarem os primeiros lugares no vestibular. A universidade - ponto alto do sistema de ensino - constitui-se, portanto, em um espaço estratégico na formação da liderança de um país e na ascensão social de grupos minoritários ${ }^{4}$.

A ação afirmativa emerge assim, como uma política pública que tem propósito, metas e alcance definidos. Não se trata de uma concessão a pessoas carentes, nem de um favor a excluídos. Trata-se antes de uma política de inclusão sim, com fulcro na dívida da sociedade para com os afrodescendentes e no compromisso político de se combater as mazelas produzidas pelo racismo estrutural que inviabiliza o processo democrático brasileiro.

No exame dos jornais daquele período, pode-se observar que a negação pura e simples do racismo não chegou a ser uma posição forte nos textos de qualquer dos gêneros de discurso pesquisados. Em geral, as desigualdades raciais são reconhecidas como uma das mazelas históricas e problema crônico da realidade social brasileira. Esse ponto é quase consensual entre os participantes do debate: leitores, editorialistas, articulistas, cronistas e também entre personalidades públicas, profissionais, técnicos do governo, especialistas e outras pessoas entrevistadas.

As divergências surgem quanto ao tipo de solução proposta para a erradicação do 'abismo' das desigualdades raciais (expressão usada pela Folha de S. Paulo). De um lado, os defensores da ação afirmativa propõem políticas públicas de recorte racial, ou seja, políticas que levam em conta o problema racial e estabelecem medidas específicas para atingir esse problema, entre elas as cotas. De outro, há os que pretendem corrigir esse tipo de desigualdade com políticas públicas universalistas, ou seja, com enfoque sobre faixa de renda ou classe social, mas sem recorte racial. Entendem essas pessoas que - sendo os negros a maioria entre os mais pobres - ao se adotar benefícios para os pobres, aqueles serão automaticamente contemplados. Entre as medidas nessa

\footnotetext{
${ }^{4}$ Para uma melhor discussão sobre o papel da universidade na ascensão social dos afrodescendentes no Brasil ver o trabalho de M. D. P. Teixeira, Negros na universidade (2003), em especial a Introdução e o Capítulo 1.
} 
perspectiva estariam a concessão de bolsas de estudo para estudantes carentes e o fortalecimento da escola pública.

De imediato, deve-se admitir que a implantação de políticas públicas para a eliminação das desigualdades raciais não exclui ou inviabiliza a adoção de políticas universalistas. Elas não são antagônicas, ao contrário, podem ser complementares. O fato é que a realidade do racismo mostra que o mesmo se manifesta entre pessoas que compartilham uma mesma situação social. Assim, entre pessoas numa mesma faixa salarial ou grau de instrução, os negros aparecem em desvantagem. É o que já dizia o movimento negro e o que vêm apontando estudos e pesquisas realizados nos últimos anos. Critérios subjetivos, reprodução do estigma da cor por meio de piadas e estórias pejorativas, associações de mitos e atribuição de imagens negativas atuam de forma intensiva sobre a auto-estima dos negros como indivíduos e como grupo social e acabam por influenciar padrões de escolha de profissionais no mercado de trabalho. O propósito da ação afirmativa é justamente intervir nessa realidade impedindo a manutenção desse rolo compressor contra a ascensão dos negros na sociedade brasileira.

\section{ANÁLISE DO DISCURSO EM FAVOR DAS MINORIAS - POSSIBILIDADES DE ATUAÇÃO}

Recusando o pretenso distanciamento advogado por grande parte dos cientistas sociais, muitos analistas do discurso defendem que o conhecimento científico seja posto a serviço da mudança social, uma mudança que venha a favorecer os grupos excluídos do poder, garantindo-lhes acesso ao poder e desmantelando mecanismos de reprodução de sistemas políticos e culturais opressores. Nessa perspectiva, defendo, assumir-se como analista do discurso subentende uma crítica implícita da realidade social. Uma crítica que seja bem fundamentada pressupõe uma alternativa ao objeto da crítica. Como propõem Caldas-Coulthard \& Coulthard (1996:xi, apud Widdowson, 2000: 155):

A Análise de Discurso Crítica é essencialmente política no propósito de seus praticantes agirem no mundo para transformá-lo e desse modo ajudarem a criar um mundo em que as pessoas não são discriminadas em razão de sexo, credo, idade ou classe social. 
Em vez de voltar-se para a linguagem como um fenômeno isolado, à parte da realidade social dos falantes, muitos analistas do discurso querem, por meio de seu trabalho, dar prioridade aos sujeitos excluídos, constituídos por ela, pessoas que têm problemas concretos no dia-a-dia até mesmo pela forma como a linguagem os classifica, rotula, fecha caminhos e limita sua liberdade de ser e agir no mundo. Assumida tal postura, a questão passa a ser de ordem prática, ou seja, examinar cada situação concreta e identificar mecanismos apropriados de intervenção em favor dos grupos minoritários. Falamos de estratégias de atuação. Tais estratégias pressupõem compromisso ético e político. Não podem ser vistas como modismos, mas como uma postura de um pesquisador que entende ser sua obrigação pôr o conhecimento adquirido em favor da mudança social com o equilíbrio de quem sabe ser a realidade social uma construção processual.

Assim é que defendemos, em primeiro lugar, buscar a perspectiva do outro, as questões de seu interesse, o atendimento de suas expectativas e necessidades dentro da área de atuação que é o discurso e, no presente caso, o discurso da imprensa. O exame sistemático dos textos da imprensa deve ser realizado, considerando as construções lingüísticas, os aspectos semânticos, as escolhas lexicais, as construções sintáticas. Essas opções de uso da linguagem devem ser identificadas e analisadas à luz do contexto social, das questões de ordem ideológica, da corrente política dominante na sociedade em foco.

Deve-se ainda considerar aspectos como a diversidade de gêneros discursivos, as especificidades das empresas jornalísticas e outras questões pontuais. Necessário também se faz o exame específico de questões conjunturais tratadas pela imprensa envolvendo as minorias, como estas são representadas, que sentidos são construídos e atribuídos a elas etc.

Outro aspecto a ser perseguido é a necessidade de se pesquisar e acompanhar a presença de jornalistas oriundos de minorias nas redações, avaliar as diferenças de enfoque nas matérias, relacionar presença/ausência de jornalistas não oriundos das elites e o tratamento favorável/desfavorável dado a esses grupos pelos veículos da imprensa.

Em segundo lugar, o conhecimento produzido nesse percurso e as implicações dele para a luta democrática não podem, não devem ser confinados nos limites estreitos da academia. Há que se partilhar os saberes adquiridos 
com os principais interessados nessas descobertas. É preciso assim municiar os grupos minoritários com dados e informações sobre o racismo, as análises desenvolvidas, as implicações discursivas, os desdobramentos teóricos havidos etc. Ou seja, pôr em comum com os excluídos o conhecimento sobre a realidade social.

Em terceiro, as informações recolhidas devem motivar a apresentação de propostas de mudança na legislação, municiar a prática de intervenção política dessas minorias, a luta por políticas públicas e por visibilidade social, o que deve ensejar, por conseguinte, mecanismos de fortalecimento da auto-estima dessas minorias.

A análise do discurso da imprensa sob a perspectiva de defesa das minorias deve ensejar, em quarto lugar, o acompanhamento crítico dos sentidos e imagens associados às minorias, propugnando então pela eliminação daqueles com conteúdo racista, preconceituoso e ofensivo.

Enfim, enveredar pelos caminhos da análise do discurso crítica deve possibilitar-nos o diálogo com outras áreas do conhecimento humano, pondo o estudo da linguagem a serviço de um desenvolvimento teórico mais abrangente. Permite-nos também um fazer ciência de modo compromissado com a mudança social. De sorte que o conhecimento produzido tenha conseqüências práticas e positivas na vida das pessoas excluídas.

\section{UM TEXTO EM EXAME}

Vamos examinar, a seguir, o caso de uma reportagem da Folha de S. Paulo, de 28 de fevereiro de 2003, que fala de um estudante negro que foi aprovado em primeiro lugar no vestibular para medicina - um dos cursos mais concorridos do país - da Universidade do Estado do Rio de Janeiro, UERJ, uma das primeiras instituições de ensino superior pública a implantar a política de cotas para negros e alunos provenientes de escolas públicas. 
1 Na era das cotas, negro é o $1^{\circ}$ em medicina

2 A Uerj, do Rio, divulgou os resultados do primeiro exame com

3 reserva de vagas para estudantes negros e pardos

4 ANTÔNIO GOIS

5 SABRINA PETRY

6 DA SUCURSAL DO RIO

8 Um estudante de 25 anos, que se autodeclarou negro e concluiu os

9 ensinos fundamental e médio em escolas públicas da zona oeste do

10 Rio, conseguiu o primeiro lugar em medicina e a terceira posição

11 no ranking geral do vestibular da Uerj (Universidade do Estado do

12 Rio de Janeiro), o primeiro com reserva de vagas para estudantes

13 negros e pardos ou que estudaram em colégios públicos.

14 Daniel Araújo Fernandes, morador de Bangu (zona oeste do Rio),

15 inscreveu-se no vestibular pelo sistema de cotas, mas o considera

16 uma "muleta". No seu caso, as cotas não foram determinantes

17 para que conseguisse entrar na universidade. Sua pontuação foi

18 de 98,25 , sobre um total de 100 , apenas um ponto abaixo do

19 primeiro lugar geral.

20 "Eu me inscrevi pelas cotas para ter uma certa tranquilidade. Sa-

21 bia que passaria por causa do meu preparo e dedicação. Mas não

22 acredito que as cotas sejam capazes de resolver o problema." $\mathrm{Na}$

23 sua opinião, o sistema é "um paliativo", que pode até ajudar muitas

24 pessoas de imediato, mas não resolverá a questão da inserção do

25 negro na sociedade. "O que precisa acontecer mesmo é a recupe-

26 ração da escola pública. Sem isso, não haverá sistema de cotas que

27 resolva", completa.

28 Este foi o quarto vestibular de Fernandes. Na sua avaliação, a con-

29 quista só foi possível porque ele fez um curso preparatório durante

30 todo o ano passado. O cursinho, feito com bolsa, é um dos mais

31 conceituados do Rio.

32 "Se dependesse só do que aprendi na escola pública, não teria a

33 menor chance, assim como não tive nos outros anos. $\mathrm{O}$ aluno de

34 colégio público não tem como concorrer com os que estudaram em 
35 colégios particulares."

36 Filho de pais aposentados pelo Estado - a mãe, professora de ensino

37 fundamental, e o pai, inspetor de um colégio público - e que não

38 têm diploma de curso superior, ele sabe que terá dificuldades para

39 terminar a faculdade.

40 Como os irmãos - a mais velha, de 30 anos, formada em pedagogia,

41 e o irmão, que cursa matemática na Uerj, ele teve que trabalhar assim

42 que concluiu o ensino médio, apesar do incentivo dos pais para que

43 fizesse uma faculdade. Fernandes entrou para o Exército e começou

44 a juntar dinheiro para ajudar a família e também para fazer uma

45 poupança que seria usada nos anos em que estivesse tendo aulas na

46 faculdade e não pudesse trabalhar.

47 Mesmo sendo o curso de medicina integral, ele sabe que precisará

48 trabalhar para custear seus gastos, uma vez que os pais não têm di-

49 nheiro para bancá-los. Dará aulas de mergulho nos finais de semana

50 e trabalhará como auxiliar de enfermagem - ocupação adquirida no

51 Exército - em regime de plantão em alguns hospitais.

52 Depois de saber do resultado, Fernandes foi à praia da Barra da

53 Tijuca comemorar com uma amiga a classificação.

54 Contrastes

55 O primeiro lugar geral no vestibular na Uerj, Renato Turita Paes

56 Leme, 18, tem um perfil bastante diferente. Morador de Botafogo,

57 bairro da zona sul da cidade, ele estudou a vida inteira numa escola

58 particular bastante conceituada, também da zona sul.

59 Paes Leme nem precisou fazer um cursinho para o vestibular. Nesta

60 sua primeira tentativa, para a faculdade de matemática, conseguiu

61 um total de 99,25 pontos. Paes Leme não seguiu a carreira dos pais,

62 ambos médicos, e nunca precisou trabalhar. 
O título da reportagem refere-se a um fato positivo: a conquista do primeiro lugar no curso de medicina - sem dúvida, um dos cursos de maior prestígio na sociedade brasileira e que, por isso mesmo, propicia muitas vezes a maior disputa por vaga no vestibular. O feito é minimizado ou até mesmo desqualificado pela inserção do adjunto adverbial de tempo - 'na era das cotas' - que ganha ainda maior relevo haja vista a inversão frasal que o deslocou para o início da oração. O efeito lingüístico-discursivo fixado pela construção leva ao pressuposto de que o estudante só conseguiu tal proeza porque foi beneficiado pelas cotas. Sustenta o pressuposto a polêmica alimentada pela imprensa.

Longe de se restringir a uma mera informação temporal, a expressão 'na era das cotas' coopera para diminuir o mérito do estudante. $\mathrm{O}$ fato é que no segundo parágrafo da matéria a interpretação sugerida no título não se sustenta como se pode ver, a partir da linha (doravante 1.) 13: "No seu caso, as cotas não foram determinantes para que conseguisse entrar na universidade. Sua pontuação foi de 98,25 , sobre um total de 100, apenas um ponto abaixo do primeiro lugar geral." Ou seja, a proeza de ter sido o terceiro lugar na classificação geral e o primeiro no disputadíssimo curso de medicina fica em segundo plano diante do fato de que o estudante é negro e inscreveu-se pelas cotas. Nesse caso, mesmo quando a política de cotas não veio para alterar a situação, a circunstância é lembrada e ocorre no texto como se fosse a responsável pela conquista do estudante negro.

Nota-se, nesse caso, uma incongruência entre o sentido construído pelo título e o sentido presente no texto da matéria, o que sugere um mecanismo de controle interno nas redações. Assim, mesmo quando o repórter desenvolve o texto de modo coerente com aquilo que apurou, o título pode indicar sentido distinto, de acordo com a perspectiva editorial que o veículo vem assumindo, no caso em apreço, de condenação à política de cotas.

Outro aspecto a ser observado é que o próprio beneficiado pelas cotas não se sente muito confortável nessa condição. Ele como que justifica o fato de ter se inscrito pelas cotas (1.16): "Eu me inscrevi pelas cotas para ter uma certa tranqüilidade". Sua opinião sobre as cotas é de lamento. Diz que se trata de uma 'muleta', 'um paliativo'. Sua opinião é resumida pelo jornal em discurso indireto $(1.18,19)$ : "pode até ajudar muitas pessoas de imediato, mas não resolverá a questão da inserção do negro na sociedade". Ou seja, o beneficiado 
lamenta a política de cotas. Pode-se deduzir que se ele soubesse a pontuação que alcançaria não teria recorrido às cotas.

Nesse texto, a imagem da ação afirmativa resulta pálida, desprovida de seu significado histórico e político, condizente com a versão que a aponta como "um mal necessário". Até mesmo o beneficiado surge na reportagem como alguém incomodado com a tal política reverberando outro lugar-comum dos críticos das cotas: sobre os beneficiados pesará a pecha de pessoas que receberam um favor, que não se mostraram capazes de passar no vestibular por seus próprios méritos. Ora, cotas não é isso. É antes uma política pública devida, conseqüente, justa nos seus fundamentos e propósitos. Seus beneficiados não têm porque sentir-se envergonhados. Vergonha deveria sentir quem os critica uma vez que, pelo menos, demonstram desconhecer aspectos essenciais sobre a história do país, a realidade do racismo ou o que sejam justiça e democracia efetivas.

O beneficiado pelas cotas, Daniel Fernandes, é apresentado como filho de uma família pobre e morador da zona oeste, em um bairro pobre. Nem o pai, nem a mãe tem curso superior. Sempre estudou em escola pública. Depois de ter concorrido, sem sucesso, em três vestibulares, ele considera que só conseguiu ser aprovado dessa vez porque $(1.22,23)$ "fez um curso preparatório durante todo o ano passado. O cursinho, feito com bolsa, é um dos mais conceituados do Rio". Também é dito que o estudante precisou antes servir ao Exército para (1.32-34) “juntar dinheiro para ajudar a família e também para fazer uma poupança que seria usada nos anos em que estivesse tendo aulas na faculdade e não pudesse trabalhar". No entanto, descobre que a história é outra (1.35-38): "sabe que precisará trabalhar para custear seus gastos, uma vez que os pais não têm dinheiro para bancá-los. Dará aulas de mergulho nos finais de semana e trabalhará como auxiliar de enfermagem - ocupação adquirida no Exército em regime de plantão em alguns hospitais".

O contraponto ao esforço desprendido pelo estudante negro para chegar aonde chegou é relatado nos dois últimos parágrafos do texto - que aparecem sob o intertítulo Contrastes. $\mathrm{O}$ aluno que conquistou o primeiro lugar geral - Renato Turita Paes Leme - já no primeiro vestibular a que se submeteu é mostrado como filho de pais médicos, morador de um bairro de classe média, que sempre estudou em escola particular 'bastante conceituada' e que nunca 
precisou trabalhar. Não é apresentada sua opinião sobre a política de cotas. Seria interessante sabê-la.

Há, portanto, uma diferença de tratamento. O beneficiado pelas cotas é questionado sobre a medida, já o outro aluno não. Tal diferença é um reforço da pecha atribuída aos beneficiados. Como se sobre eles pesasse sempre o dever de se explicar ou mesmo justificar o ingresso na universidade.

As trajetórias distintas são apresentadas, mas o contraste em si não é explorado no texto. $\mathrm{O}$ fato mesmo da desigualdade cruel que abre as portas da universidade para uns e fecha para outros é deixado de lado na matéria. São apresentados dois jovens que conquistam os primeiros lugares no vestibular. As distinções no percurso de vida de cada um deles são exploradas como 'contrastes', mas não se dá a esse fosso social o nome de racismo. Se não se trata de racismo, seriam apenas diferenças numa sociedade 'naturalmente' desigual? Há, portanto, um silenciamento sobre questões básicas desse processo social e político.

\section{Considerações finais}

Recorrer à análise do discurso - em suas diversas perspectivas -, como um instrumental teórico-prático de exame da realidade social, será de grande proveito à luta em favor da democracia no campo específico da linguagem quando aponta as injunções ideológicas presentes e atuantes nas estruturas lingüístico-discursivas que, de outra sorte, poderiam passar por naturais. Erigida no campo da lingüística e enriquecida por considerações, categorias e conceitos trabalhados pelo materialismo histórico, a análise do discurso, seja em sua vertente francesa, britânica ou outra, tem muito a contribuir no exame, identificação e luta contra as desigualdades e a opressão existentes na sociedade no e por meio do discurso.

A ausência de vozes de grupos minoritários, a sub-representação ou a representação estereotipada ou sistematicamente negativa constituem - sem prejuízo de outro tipo de consideração - aspectos flagrantes do investimento ideológico na linguagem. A simplificação, o silenciamento sobre aspectos do processo social, a naturalização e outros mecanismos ideológicos presentes nos textos produzidos por profissionais da imprensa evidenciam as vinculações de ordem ideológica que operam no processo discursivo da imprensa, fazendo com que a representação das minorias na imprensa apareça desvinculada da 
realidade das práticas racistas onipresentes. Por vezes, como vimos na análise do texto, até mesmo conquistas encetadas por membros de grupos minoritários são exploradas de forma negativa, de modo a desqualificar o sucesso alcançado, como no caso do estudante.

Um aspecto a se observar é que o processo social e político que faz das relações raciais e do racismo temas-tabu na sociedade brasileira instaura e faz circular no discurso da imprensa uma preocupação - manifesta por muitos - quanto a ser acusado de racista ou um certo temor de parecer indiferente à sorte de milhões de brasileiros em situação de carência, excluídos que estão do usufruto de bens simbólicos, como o acesso à universidade. De sua parte, os que se levantam contra o racismo enfrentam um problema prático, o tema simplesmente ainda não goza de um reconhecimento público geral, evidenciado no fato de que não é priorizado como um problema grave, cujo combate requer políticas públicas específicas. $\mathrm{O}$ texto analisado mostra como o assunto é tratado predominantemente dentro dos limites estreitos da política de ensino no Brasil.

A imprensa - por suas características peculiares de instituição social forçada a veicular as muitas vozes da esfera pública - emerge como um espaço privilegiado de formulação e fixação de sentidos e de disputa do consenso em torno do assunto. $\mathrm{O}$ discurso da imprensa sobre as cotas explicita tanto uma oportunidade de construção quanto de combate a essa legitimidade. Assim, se o processo de implantação da política de cotas é ocasião para se enfrentar concretamente efeitos perversos do racismo, a discussão do tema na esfera pública traz a lume o racismo subjacente nos sujeitos e nas práticas sociais.

No tocante à contribuição específica dos analistas do discurso para o avanço da democracia nesse particular entendemos ser de fundamental importância: a) desenvolver investigações do discurso da imprensa voltado aos grupos minoritários, buscando evidenciar as desigualdades nos padrões de acesso ao discurso da imprensa, na representação desfavorável desses grupos, no uso de expressões e imagens associadas às minorias etc.; b) municiar os grupos minoritários com informações teórico-práticas que os auxiliem na compreensão do racismo discursivo; c) apontar no discurso da imprensa usos e práticas lingüístico-discursivos que sejam prejudiciais a essas minorias; d) auxiliar na construção de contrapontos às perspectivas lingüístico-discursivas desfavoráveis às minorias, apoiando a resistência desses grupos nesse particular. 
Sem dúvida, não é simples pautar o assunto tanto na imprensa, como na esfera pública de um modo mais abrangente. Nesse sentido e malgrado o conjunto das manifestações de agressividade e discriminação veiculadas nos textos da imprensa, implícita e explicitamente, a discussão sobre a viabilidade da política de cotas como uma medida de combate ao racismo no Brasil é um bom presságio. Evidencia que o assunto não está resolvido e incomoda bastante. E, se incomoda, é de se supor que as feridas do passado não têm sido devidamente tratadas.

\section{REFERÊNCIAS BIBLIOGRÁFICAS}

BAGDIKIAN, B. H. O monopólio da mídia. Trad. M. M. de F. Ribeiro. São Paulo: Página Aberta, 1993.

CHOULIARAKI,L.\& N.FAIRCLOUGH. Discourse in late modernity: rethinking critical discourse analysis. Edinburgo: Edinburgh University Press, 1999.

FAIRCLOUGH, N. Discurso e mudança social Trad. I. Magalhães et alii. Brasília: Editora Universidade de Brasília, 2001.

LAW, I. Race in the news. Nova Iorque: Palgrave, 2002.

MARTINS, A. R. N. A polêmica construída: racismo e discurso da imprensa sobre a política de cotas para negros. Tese de doutorado inédita. Universidade de Brasília, 2004.

TEIXEIRA, M. D. P. Negros na universidade: identidade e trajetórias de ascensão social no Rio de Janeiro. Rio de Janeiro: Pallas, 2003.

THOMPSON, J. B. Ideologia e cultura moderna: teoria social crítica na era dos meios de comunicação de massa. 2ed. Petrópolis: Vozes, 1998.

TOURAINE, A. Crítica da modernidade. Trad.: E. F. Edel. Petrópolis: Vozes, 1999.

VAN DIJK, T. A. Racism and the Press. Londres: Routledge, 1991.

VAN DIJK, T. A. Discourse, power and access. In: C. R. Caldas-Coulthard $\&$ M. Coulthard (orgs.) Texts and Practices: readings in critical discourse analysis. Londres; Nova Iorque: Routledge, 1996.

WIDDOWSON, H. Critical practices: on representation and the interpretation of text. In: S. Sarangi \& M. Coulthard (orgs.) Discourse and social life. Harlow: Pearson Educatio Limited, 2000. pp.155-169. 